\title{
BMJ Open Multilevel model of stigma and barriers to cancer palliative care in India: a qualitative study
}

\author{
Richard Harding, ${ }^{\oplus 1,2}$ Shoba Nair, ${ }^{2}$ Maria Ekstrand ${ }^{3,4}$
}

To cite: Harding R, Nair S, Ekstrand M. Multilevel model of stigma and barriers to cancer palliative care in India: a qualitative study. BMJ Open 2019;9:e024248. doi:10.1136/ bmjopen-2018-024248

- Prepublication history for this paper is available online. To view these files, please visit the journal online (http://dx.doi. org/10.1136/bmjopen-2018024248).

Received 17 May 2018 Revised 2 January 2019 Accepted 8 January 2019

Check for updates

(C) Author(s) (or their employer(s)) 2019. Re-use permitted under CC BY-NC. No commercial re-use. See rights and permissions. Published by BMJ.

${ }^{1}$ Florence Nightingale Faculty of Nursing Midwifery and Palliative Care, Department of Palliative Care, Policy and Rehabilitation, King's College London, London, UK

${ }^{2}$ Department of Pain and Palliative Medicine, St John's Medical College Hospital, Bangalore, Karnataka, India

${ }^{3}$ Division of Prevention ScienceDepartment of Medicine,

University of California San

Francisco, San Franscisco,

California, USA

${ }^{4}$ St John's Research Institute, Bangalore, Karnataka, India

Correspondence to

Richard Harding;

richard.harding@kcl.ac.uk

\section{ABSTRACT}

Introduction Palliative care coverage and opioid consumption in India are relatively low compared with global data. The literature suggests commonplace concealment and collusion in withholding information, but these hypotheses lack evidence.

Objectives This study aimed to develop an explanatory evidence-based model of stigma, communication and access to cancer palliative care in India that can be used to develop, test and implement future interventions. Design This cross-sectional qualitative study sampled advanced cancer patients $(n=10)$, their family caregivers $(n=10)$ and oncologists $(n=10)$. Grounded theory procedures were utilised to analyse transcripts, and a theoretical model generated.

Setting A tertiary teaching hospital in South India. Results The model explains how stigma associated with communicating a diagnosis of advanced cancer is enacted by treating oncologists, family members and community. This leads to patient expectations of cure and futile treatment uptake. Patients commonly only present needs with respect to pain, not within psychological, social or spiritual domains, likely due to the lack of patients' insight into their diagnosis and prognosis. As a result of oncologists' and families' unwillingness to disclose the prognosis, and patient focus on pain due to their lack of insight, palliative care clinicians view their services as under-utilised, and patients perceive palliative care as a pain management service that is not 'different' from other clinical services. Advanced care needs and purchase of futile treatments lead to lost employment among families, increased family debt and high care costs, which are rarely disclosed due to their unwillingness to discuss their needs. Conclusion Our novel theoretical model is an essential first step to ensure that complex interventions are plausible, with mechanisms of action that address the needs of relevant stakeholders. A family-centred approach with an oncology workforce skilled in communication and an enabled patient population could increase access to palliative care, and improved outcomes may be attainable.

\section{BACKGROUND}

Low-income and middle-income countries (LMIC) are predicted to bear $70 \%$ of global cancer cases by $2030 .{ }^{1}$ As LMIC industrialise, cancer incidence is predicted to rise fivefold. ${ }^{2}$ Clinicians anticipate poorer cure rates compared with high-income countries due
Strengths and limitations of this study

This is the first study to identify drivers for poor endof-life care access from the perspective of patients, families and professionals in India.

- The inclusion of all stakeholders optimise the potential for strategies to improve care for people with advanced disease.

- The data are collected from one city in India and so the study may need replication in other parts of this diverse country.

- We did not directly observe clinical encounters and so cannot verify information-giving behaviours by clinicians.

to late presentation, lack of locally adapted protocols and fewer resources. ${ }^{3}$ Similarly, the provision of palliative care is woefully inadequate in LMIC, where the majority of palliative and end-of-life care is needed, due to later presentation, fewer curative options, ageing populations and rising cancer incidence. ${ }^{4}$

Palliative care is a global human right, ${ }^{5}$ to be provided 'throughout the illness course' within LMIC. ${ }^{6}$ The World Health Assembly resolution 67.19 calls for palliative care 'integrated throughout the life course'. ${ }^{7}$ The most recent iteration of the WHO Universal Health Coverage goals calls for the "full spectrum of essential, quality health services, from health promotion to prevention, treatment, rehabilitation, and palliative care. ${ }^{8}$

There were an estimated 815100 cancer deaths in India during $2016 .^{9}$ The WHO's Global Report categorises India as lacking integrated palliative care, ${ }^{10}$ with patchy activity. ${ }^{11}$ Lack of prioritisation of palliative care at the governmental level hampers adequate policy responses, resulting in restrictive regulation..$^{12}$ Opioid consumption in India for cancer pain relief is comparatively very low, with annual morphine equivalent milligrams per capita of 0.2377 , compared with the global average of $58.11 .^{13}$ A systematic review of the state of evidence 
for palliative care in India found very little evidence to inform appropriate models of care. ${ }^{14}$

As in many other LMIC, Indian households affected by cancer report lower workforce participation, and higher rates of borrowing and asset sales, compounding their poverty. ${ }^{15}$ Most out-of-pocket expenses are on futile investigations, treatment and expensive diagnostics. ${ }^{16}$ While most Indian cancer patients prefer to know their diagnosis, around one-quarter do not, and would prefer information to be communicated only to family members. Research is thus needed to identify the best ways to help guide physicianpatient and physician-family communication. ${ }^{17}$ Understanding cultural beliefs that shape access and delivery of cancer palliative care in India is essential to formulating an appropriate response, ${ }^{18}$ but unfortunately, very little data currently exist to inform such a response. A qualitative study of oncologists in India suggests poor understanding among patients of the meaning of a cancer diagnosis, fear of contagion and hopelessness in face of the diagnosis, ${ }^{19}$ with professionals sharing information with family members who then often make care decisions without involving the patient. It should be noted that these data were collected primarily in the context of communicating cancer diagnosis, not poor prognosis, and did not seek patient or family views.

The lack of awareness of prognosis and diagnosis among patients and poor coverage of palliative care in India is at odds with evidence that the vast majority (92\%) of Indian cancer patients would wish to know the chance of a cure. ${ }^{20}$ It is thus essential to understand the mechanisms that drive current communication practices and poor palliative care access. Among cancer populations in the USA, patient-doctor communication is negatively affected in patients with lung cancer due to stigma. ${ }^{21}$ A small study of cancer survivors, oncologists and the general population cancer in India perceived both community and internalised stigma to be driven by their own and others' beliefs that cancer is the result of sins of the past life, with social rejection due to the lay belief that cancer is an infectious disease. ${ }^{22}$

An explanatory model is needed that draws on the perspectives of advanced cancer patients, families and clinicians. This may explain the potential role of stigma in communication and identify potential responses to increase access to, and delivery of, appropriate and effective palliative care. The development of such a model will enable feasible acceptable and appropriate interventions to be developed and evaluated.

This exploratory study aimed to meet this need by developing an explanatory evidence-based model of stigma, communication and access to cancer palliative care in India that can be used to develop, test and implement future interventions.

\section{METHODS}

\section{Design}

This cross-sectional, qualitative study used samples drawn from multiple populations, including advanced cancer patients, their family caregivers and oncologists to inform a triangulated model across key stakeholder primary data.

\section{Sample and setting}

The current exploratory study was undertaken at a 1350bed tertiary teaching and referral hospital in South India. Patients and their family members were referred to the study either by the nurse or the medical resident in the department of pain and palliative care. Patient eligibility criteria included being at least 18 years old, having a cancer diagnosis, being referred to the palliative care department, understanding and speaking either English or Kannada (the local language) and having an adult family member who was willing to be interviewed about their caregiving needs and experiences with palliative care. Family eligibility criteria included being at least 18 years old, caring for a patient who met the criteria above and consenting to data collection. In addition, they had to meet the following definition of informal caregiver, ie, 'unpaid, informal providers of one or more physical, social, practical and emotional tasks. In terms of their relationship to the patient, they may be a friend, partner, ex-partner, sibling, parent, child or other blood or non-blood relative'. ${ }^{23}$ Oncologists interviewed were contacted directly by a faculty member in the department of pain and palliative medicine and had to have previously referred patients for palliative care. Our purposive sampling frame addressed the following characteristics: patient age, gender and primary malignancy, family caregiver relationship to patient and clinical practice, with 10 per group (ie, patient, family member, oncologist) to enable emergence of themes and integration of the stakeholder groups. The interviews were conducted over a 12 month period, starting in February 2017.

\section{Procedures}

The referring palliative medicine staff member introduced interested patients and family members to a study staff member, who explained the purpose of the study and obtained informed consent. The interviews were conducted in a private setting, separately for patients and family members, in the language of the participant's preference and typically took between 30 and $45 \mathrm{~min}$.

Semi-structured interviews were conducted by trained local Indian research staff members, who had a master's degree in psychology or social work. Interviewers were independent of the referring clinic and had no prior interaction or relationship with the participants. The interview guides were forward and back translated to ensure semantic equivalence ${ }^{24}$ and addressed the patients' understanding of advanced disease, fears, social dimensions of disease (eg, how cancer death may be socially stigmatised), their communication with family, friends and oncologists, their understanding, fears and acceptability of opioids and concepts of incurable disease and palliation. The topic guide for family members addressed their understandings of advanced disease, fears, social dimensions of disease, communication with oncologists 
and information sharing/withholding from patients, their understanding of opioids and their fears and acceptability and concepts of incurable disease and palliation. The interviews with oncologists addressed the role of stigma around death, dying and opioid use in clinical management, disclosure, communication with patients and families, challenges to pain relief and the perceived potential dangers and benefits of different treatment strategies. Patients and their family caregivers were interviewed separately to enable participants to express views as freely as possible.

\section{Data management and analyses}

All interviews were digitally recorded, transcribed verbatim in local language by bilingual research staff and translated into English at the Indian site, if needed, prior to grounded theory analysis. This method was selected in line with our study aim of developing a novel explanatory evidence-based model of stigma and access to cancer palliative care for subsequent testing. Transcripts were then anononymised (eg, potentially identifying information removed) emailed to the other research team members in the UK and USA. Following reading and familiarisation with the transcripts, an initial coding frame was developed with line-by-line coding (ie, data reduction) of the entire data set (ie, patients, families and staff) by one researcher $(\mathrm{RH})$ and the individual transcript coding and proposed frame were then reviewed by a second researcher (ME) and refined through consensus. ${ }^{25}$ We then integrated the codes to develop the novel explanatory model (ie, data complication). The coding frame, resultant model and interpretation were then discussed with the third researcher $(\mathrm{SN})$, and agreed through consensus.

\section{Public and patient involvement}

Public and patients were not involved in the design or conduct of this research. This reflects the lack of patient advocacy currently in this field in India.

\section{RESULTS}

\section{Sample description}

Our planned sample size was met, with sample diversity achieved through the purposive sampling approach. Patient age ranged from 40 to 74 , with a majority of female patients $(n=7 / 10)$ (table 1$)$. The primary malignancy was cervix $(n=3)$, ovary $(n=1)$, hepatocellular $(\mathrm{n}=1)$, adenocarcinoma $(\mathrm{n}=1)$, breast $(\mathrm{n}=1)$, stomach $(\mathrm{n}=1)$ and cholangio carcinoma $(\mathrm{n}=1)$. The family caregivers were largely male and were children and spouses of the patient. Oncologists spanned surgical, gynaecological, pulmonology and radiation oncology with a range of 2-35 years of clinical practice.

\section{Main findings}

In figure 1 we present the explanatory model generated from the data. In summary, the model explains how the stigma associated with communicating a diagnosis of

\begin{tabular}{|c|c|c|}
\hline \multicolumn{2}{|l|}{ Patients and families } & \multirow{2}{*}{$\begin{array}{l}\text { Family member: } \\
\text { relationship to } \\
\text { patient }\end{array}$} \\
\hline Patient gender & Patient age & \\
\hline Female & $36-40$ & Son \\
\hline Female & $61-65$ & Son \\
\hline Male & $46-50$ & Son \\
\hline Female & $46-50$ & Daughter \\
\hline Male & $71-75$ & Daughter \\
\hline Male & $46-50$ & Son \\
\hline Female & $46-50$ & Son \\
\hline Female & $56-60$ & Daughter \\
\hline Female & $41-45$ & Husband \\
\hline Female & $61-65$ & Husband \\
\hline \multicolumn{3}{|l|}{ Oncologists } \\
\hline Designation & $\begin{array}{l}\text { Years of } \\
\text { qualified } \\
\text { practice }\end{array}$ & Gender \\
\hline Medical oncologist & 15 & Male \\
\hline Radiation oncologist & 30 & Female \\
\hline Radiation oncologist & 6 & Male \\
\hline Surgical oncologist & 2 & Male \\
\hline Gynaecology oncologist & 35 & Female \\
\hline Surgical oncologist & 5 & Male \\
\hline Surgical oncologist & 2 & Male \\
\hline Gynaecology oncologist & 10 & Female \\
\hline Pulmonologist & 10 & Female \\
\hline Surgical oncologist & 2 & Male \\
\hline
\end{tabular}

advanced cancer is enacted by treating oncologists, family members and the community. This leads to patient expectation of cure and uptake of futile treatment. Patients only present needs with respect to pain and none within psychological, social or spiritual domains, likely due to the lack of patients' insight into their diagnosis and prognosis. As a result of oncologists' and families' unwillingness to disclose the prognosis, and patient focus on pain due to their lack of insight, palliative care clinicians view their services as underutilised, and patients perceive palliative care simply as a pain management service that is not 'different' from other clinical services. The patient's advanced care needs and purchase of futile treatments lead to lost employment among family members, increased family debt and high care costs, which family members rarely disclosed to the treatment team due to their unwillingness to discuss their own needs.

\section{Communication and understanding}

Lack of disclosure: clinicians

Although a range of behaviours were reported by clinicians in terms of disclosure of diagnosis and prognosis, the common approach was to withhold information from 


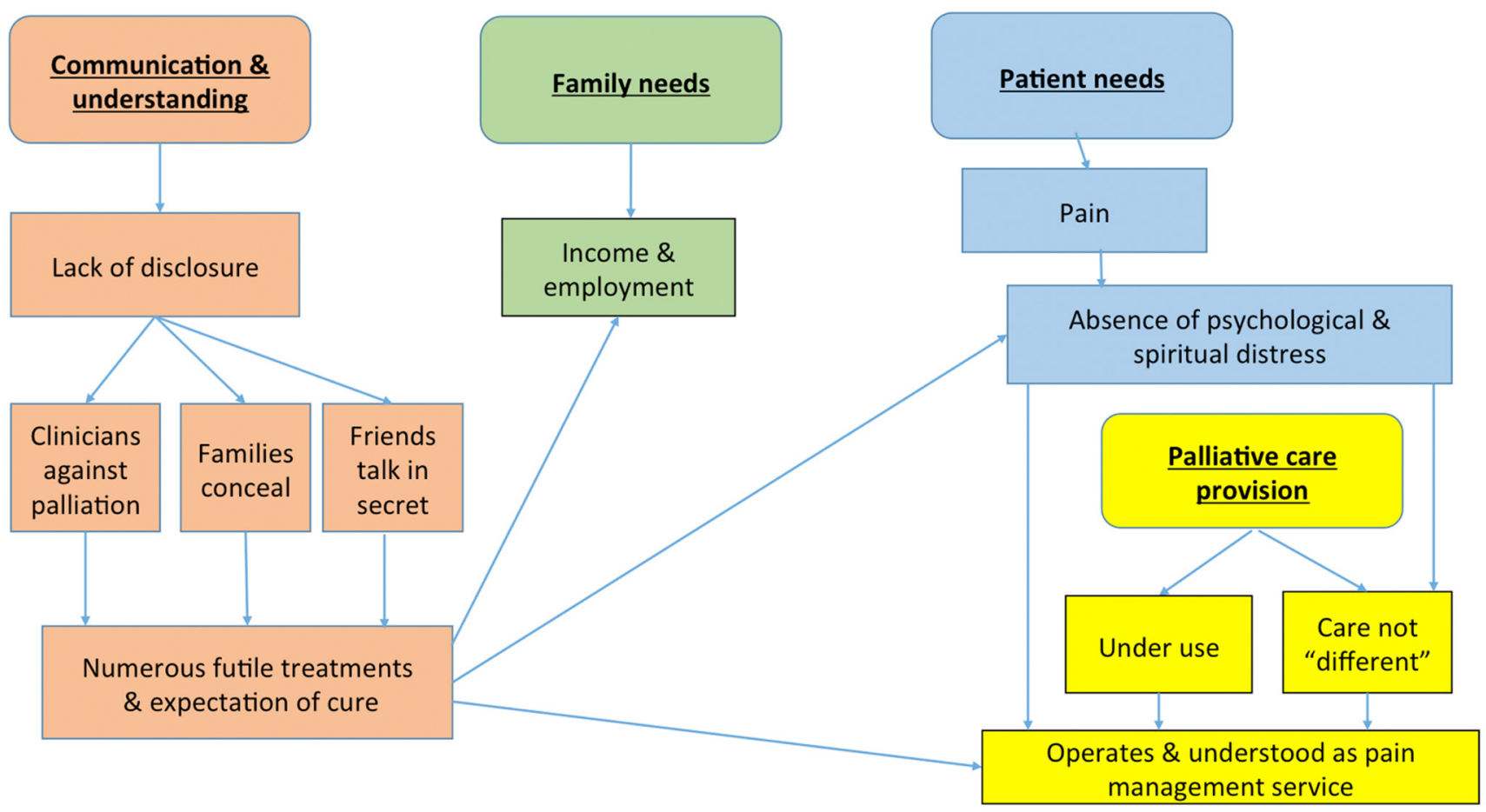

Figure 1 Explanatory model of the data.

patients, or to actively give an inaccurate account, perpetuating the stigma of discussing death within medical and lay discourse.

INTERVIEWER: Do you have patient asking you directly what is wrong with them and so how do you reply?

ONCOLOGIST: At time I will lie. 'I think you are improving or may take some more time', but I know that is not correct, but somehow, we have to balance. (Surgical oncologist)

To never share accurate information was commonplace,

INTERVIEWER: Is it anytime or numbers of time that you have to actually initiate conversations with patient or their relatives about end-of-life care?

ONCOLOGIST: Not actually...It's usually the patient family people ask like how the end is going to come, how patient is going to survive, how long he is going to survive then definitely we explain to them that how the end care will come...If the patients themselves are asking it is very, very rare, for ourselves to explain to them in such a case. (Radiation Oncologist).

This reluctance to communicate honestly with patients was not restricted to earlier in the disease trajectory.

INTERVIEWER: Do you actually have an end-of-life conversation?

INTERVIEWEE: Not really. Initially, before the recurrence we do not talk.

INTERVIEWER: No after the recurrence.
INTERVIEWEE: No. After the recurrence, also at that point of time, we don't talk about it. (Surgical oncologist).

Lack of disclosure: families

The family is a major driver in non-disclosure to the patient of the stigmatising poor prognosis. Even in cases where the clinician believed the patient should have full information, the family may override this.

We initially speak to the relatives first, and we do take their input as far as how much to inform the patient first day. But very frankly, in our country, most of the relatives do not want the diagnosis itself to be revealed to the patient, but we always make it a point to mention that the patient has to know, has to understand what is the disease, and what's happening, and the patient has to take the decision as far as therapy or palliative care, whatever the thing, the patient has to be aware. But a very strong, this thing, from the relatives not to tell the patient is put through us, most of the time, but we do make it a point that this is something that the patient has to know, but I do admit that we heed the relatives request not to reveal, or be more open to the patient. (Gynaecological oncologist)

However, some oncologists believed that their patients could manage full disclosure.

We underestimate the patient's capacity to observe the diagnosis and the treatment and side effects etcetera including the prognosis. So, because as you said the relatives first get to know the diagnosis and then get to know the treatment, prognosis etcetera. There are a lot of uncertainties in the patient's 
mind as to the diagnosis and the treatment and curability etcetera. So that has to be first addressed so if we involve the patient and take him into confidence and before we tell. This happens even in educated patients also. The relatives might be less educated than the patient, but they take the upper hand, they tell us that the patients cannot take the shock of the diagnosis etcetera. (Medical Oncologist)

By acquiescing to the family direction not to disclose, many clinicians felt that this led to poorer care later towards the end of life,

Yeah, more than the patient there is some reluctant in part of the relatives. They think if we discuss from that upfront before the time really has come for that they think the end is very close. They think that the doctor has given up on the treatment that treatment is not working so they have lot of apprehensions and negative feeling associated with those discussions. So, many a time the treating physician is forced to postpone all this really to the end of the terminally ill stage where the patient may not be in a real position to take a decision or there are a lot of social thing that go with the end of life which patient has to be given an opportunity to make decision while he is in a real state of mind to make those decisions when he is not in real pain, when he is not disoriented etcetera. (Medical Oncologist)

Even if a clinician attempts to initiate direct communication with the patient, families may physically intervene,

So many of times we know we face collusions that means our relatives are not allowing us to say the diagnosis to the patient himself. In fact, they form a physical barrier if you say right in front of us that, you know, showing us, different gestures telling us not to tell the right one. (Radiation Oncologist)

Consistent with the oncologists' reports, family members described many instances when they chose to provide untruthful information to the patient regarding their illness, motivated by good intention that the patient may better 'fight' the disease if they are unaware of prognosis

First, we have to develop a feeling in them that we are here to support them. Then we have to tell them that it is not a severe problem even though it is so, we have to tell them that if this kind of treatment is taken it will improve her health, or, if there is a pain, then if she takes a tablet it will be under control. In this way, we fill in courage in them. (Daughter of hepatocellular cancer patient)

I convinced him and got him discharged in the morning itself and got him here. The tests were done here and thought its ulcer and nothing related to cancer. Told him that it's just ulcer and not cancer and in endoscopy result, we got to know this is cancer. (Son of stomach cancer patient)

We had told her this is starting stage but it was fourth stage. She felt bad when we told its starting stage also. (Son of cervical cancer patient)
Lack of disclosure: friends

Patients and families described feeling stigmatised and socially ostracised from their community following the onset of illness,

INTERVIEWER: Your neighbours and the relatives who visit hospitals, have you faced any trouble from them?

PARTICIPANT: There are changes, since 1 month their talking and talking behind our back has changed...behaviour and all has changed. The way of talking will be different in front of them and in their back. It was different than before. (Son of cholangio carcinoma patient)

PARTICIPANT: That has become a big problem for us.

INTERVIEWER: Will you tell more about it?

PARTICIPANT: We have seen many such things. We have seen here also. Nothing has happened yet. After that only we came to hospital. In my village also no one speaks properly with us. (Husband of cervical cancer patient)

\section{Choosing futile treatment \& expecting cure}

Families and clinicians' behaviours regarding communication encouraged patients to pursue expensive and futile treatment. This exemplifies how the stigma of terminal illness can lead to adverse financial consequences for the family.

About 3-4 months back, we had shown her once or twice, and again in 2013 took treatment in Hyderabad, again in Anantpur, Hindupur, Tumkur. Wherever people say treatment will be given, we have gone there and shown her... We have visited about 10 hospitals. We have not got good results, no cure, even here. Nobody tells correctly about what has happened, what has to be done. (Son of cervical cancer patient)

What may be our main issue in our present situation? We have to save our mother. That is our main issue. What are treatments available and where? Is it here in our country or is it available in other countries? Is there treatment for this may be it is in other country? We want to find it out and give it to her and we want to save her. That is our main concern now. (Daughter of hepatocellular carcinoma cancer patient)

What to expect, if there was reduction of pain, it would have been good. They won't tell anything. They told they will put chemotherapy injection. After we said okay for it, they told that we don't give guarantee for it. One injection is Rs 15000. (Son of stomach cancer patient)

I am worried that this got this disease and how much ever we spend money on it, health is not improving. I am in this condition since 4-5 years and there is no improvement at all. I am not able to bear the pain. [Female 61-65-yearold cervical cancer patient)

By next year what I have thought is I have to get up and walk properly. I have to be like all others and walk like others and my disease should be cured. They have given me so much hopes that it will get better. I like to be like a normal person, 
by getting up and walk normally. (Female 46-50-year-old hepatocellular cancer patient)

I have to eat well if I have to do something related to my health. If I eat I will be fine. I know this 100\%. (Female 61-65-year-old adenocarcinoma patient)

\section{Patient needs}

Physical pain was the only concern described by patients and families, and was a major one for both groups. When psychological, social and spiritual needs were probed, none were described. The only social needs were the financial challenges described in relation to pursuing futile treatments (above).

However, the data do suggest that there may be psychological concerns that patients or families choose not to express to families or their clinical team.

At present, what his feeling is he has to become better and he could be help us more or if he would have listened his wife's advice it would have been better. But anyway, he is not discussing anything openly. (Daughter of lung cancer patient)

This reluctance to share may result from the perceived necessity to focus on cure and active treatment.

INTERVIEWER: We are talking about your problem. Will you tell your problems to anyone?

PARTICIPANT: No. I will not tell.

INTERVIEWER: Why you won't tell?

PARTICIPANT: Why to tell, what the use is by telling others. We only have to get it cured. We have to be quiet keeping this in our stomach, by believing god. If the ways I tell like how I am telling you, they also will spread this to other few by telling she has got big disease. They make the news big. If we eat food it will be inside your stomach, if you drink water it will be inside your stomach. Likewise why you want to tell this. You have to keep this in your stomach and be quiet. (41-45-year-old cervical cancer patient)

\section{Family needs}

The only self-reported needs among family members were employment and financial ones. The desire to seek costly treatment was described by an oncologist,

Basically all of them have financial problem if they have money then before this thing end of life I may ask 'do you want to take a second opinion?' (Surgical oncologist)

Caregiving can also lead to unemployment.

No problem as such. But the problem was of a job. When I came here to look after, I lost a job. When I came to look after my mother, my job was suspended. Other than this, no other problem. We don't want anything other than the disease getting cured. Now they are telling you need more money. We have got problem for money. (Son of ovarian cancer patient)
As with patients, families chose not to share their distress with others, which suggests that expression of emotional concerns is highly stigmatised.

INTERVIEWER: Have you ever felt sharing this after seeing him suffer?

PARTICIPANT: I don't like to tell to any relatives as we have to face our own difficulties. (Son ofcervical cancer patient)

Family members described pain management for patients as improving well-being of family members,

If pain reduces its good for us. How soon it comes down, it's good for him as well as for us. (Wife of adenocarcinoma patient)

Palliative care provision

Operates and understood as pain management

Palliative care was commonly described by oncologists to patients and families as a pain management service.

Without telling them that it is palliative care we refer to pain management. We say that, that is the pain doctor so you go there and sometimes there are symptoms which, you know, which we assumed about we tell them to go there, but we don't use the word palliative care at that time because they still have hope, they think that once you take palliative care all hope is lost. (Gynaecological oncologist)

INTERVIEWER: According to you what is palliative care?

PARTICIPANT: Palliative means pain remover.

INTERVIEWER: Is the palliative care that you are taking is different from other cares?

PARTICIPANT: No, it is not different. (Male 71-75-yearold lung cancer patient)

This led to underutilisation of the available trained specialist palliative care team.

The other problem is the availability of Palliative Care support. In fact, it has to start from the diagnosis itself, but then unfortunately most of us are underutilising wherever Palliative Care specialists are available also. The services are underutilised only we are utilising the services in terminally ill patients, End-of life-care etcetera or only for pain management. So, it becomes equal to pain management unfortunately, so that has to change. (Medical Oncologist)

As a result of poor awareness of prognosis, the focus on pain, and the labelling of the service as pain management, patients do not perceive palliative care as different to their other care, although it successfully manages pain and optimises function.

This treatment is for the body pain so that she must not experience the body pain. But this also is helping because pain is the main thing now. If medicines can be taken at any condition then it is good. If there is pain she cannot do anything. Though she cannot do her 100\%, she can do her $60 \%$ 
work. She can eat, walk, so there is some use. (Daughter of patient with hepatocellular carcinoma)

This underuse is also evidence in the management to pain, with an example of emergency room use instead of pre-emptive pain management planning.

If I tell I have small pain, my brother, daughter or son-in-law will rush me to hospital. (Female 46-50-year-old hepatocellular cancer patient)

Lastly, it was recognised that the responsibility for improving palliative care access lies with the oncologists.

The mindset has to change from the consultant himself. Unfortunately, most of us are not exposed to Palliative Care why we were doing our super specialty training itself it starts from there and most of the hospitals including hospital like (hospital name) don't have good Palliative Care team then we are not put there for training. During training we have not posted there for long enough to really know the difference that is made by the Palliative Care especially in the life of the patients and the relatives especially terminally ill patients. So, it has to start from the specialists themselves. (Medical Oncologist)

\section{DISCUSSION}

This is the first study to determine the role of stigma in advanced cancer in India, integrating primary data from patients, family members and oncologists. Although there is a literature identifying this as an area of importance and cultural specificity, it has lacked original data or an explanatory model of the mechanisms incorporating all potential actors in stigmatising processes, to inform which interventions might be theoretically plausible and acceptable.

This exploratory study has generated a novel model that identifies the role of stigma in expressing needs in advanced cancer, communication and disclosure and in accessing palliative care. The multi-level model reveals the collusion between clinical teams and families that leads to pursuit of expensive and futile treatment, poor insight on the part of patients and suboptimal use of the wide range of interventions available through palliative care teams.

Stigma is enacted and perpetuated at all levels, including by clinicians who do not openly communicate poor prognosis, family members who request this concealment and by services that are simply described as "pain management.". Interestingly, no evidence was found of 'opiophobia' among patient and families, only one of whom was aware of morphine.

The data highlight a dissonance between preference and practice, given that the vast majority of Indian cancer patients prefer to know their diagnosis ${ }^{17}$ and the chance of a cure. ${ }^{20}$ Interestingly, our data suggest that patients had problems other than pain but were unwilling to share these concerns. We have found previously among advanced cancer patients in LMIC that poor patient insight regarding diagnosis and prognosis are associated with worse self-reported well-being, ${ }^{26}$ that communicating poor prognosis is a challenge for medical staff in LMIC, ${ }^{27}$ and that decision-making is likely to be made away from the patient. ${ }^{28}$

The results of this study differ somewhat from our previous findings ${ }^{29-34}$ on the prevalence and correlates of HIV-related stigma in this region. Stigma enacted by healthcare providers and family members were driven largely by blame and fear of infection, which led to endorsement of coercive policies, such as mandatory testing and prohibitions on marriage and childbearing. It also led to unwillingness by both family members and healthcare staff to care for HIV-infected patients. While no such attitudes were reported in the current study, lack of communication was clearly an issue in the care of both patients diagnosed with HIV and with advanced cancer. Participants in both studies also reported frequent disease-related misconceptions and an unwillingness to discuss sensitive topics, such as a poor prognosis and, in both cases, family members appeared to feel ashamed over the diagnosis of their loved one. In both situations, this shame, together with misconceptions regarding the disease, fear and lack of communication likely drove stigma and led to sub-optimal treatment.

There are a number of limitations to this exploratory study. First, we did not aim to collect data on the content of the clinical encounter and therefore it may be that oncologists share information but this is poorly understood. However, our data from oncologists and family members strongly contradict that possibility, as they describe requests to conceal information. Second, our data were only collected in one private, non-profit Indian medical college hospital and we strongly recommend the expansion of this model through primary data collection in other types of institutions and multiple parts of India. Third, there may have been both a sampling and participation bias in that those with insight but a poor reaction to the information may not have consented to participate. We are not aware of any conflicts of interest in this study.

Previous studies form Pacific Asia have found that, despite popular belief, people would prefer to be given full information regarding diagnosis and prognosis. ${ }^{35-38}$ Lack of disclosure of prognosis and introduction to the goals of palliative care in this population may have an interesting outcome, in that patients are more willing to be referred to palliative care when it is described as 'pain management'. However, this must be very carefully balanced against the poor outcomes described-pursuit and payment of futile treatments, lack of disclosure of concerns, very low levels of insight and clinician views of under-use of the range of care and support available through palliative care staff.

There is evidence from the field of HIV in India that stigma-reducing interventions are wanted, feasible and acceptable. ${ }^{39-41}$ We have a number of recommendations from our findings that aim to improve access to palliative 
and end-of-life care for patients and families affected by advanced cancer in India. First, in order for patients and families to claim their right to affordable palliative care under the Universal Health Coverage, oncologists and families must enact the right to information about diagnosis and prognosis. However, this has to be done in a feasible and acceptable way and not unduly add to distress. This requires an intervention that supports families to accept and share poor prognosis with the patient and community. Second, to enable this right to information, oncologists require interventions that can enable them to handle these difficult, ongoing conversations in a way that is acceptable to families. In the context of concealed prognosis and pursuit of futile treatment, information giving must be seen as a process and not a single event. Third, building on our first two recommendations, the intervention must focus on the central information gatekeeping role of the family, who are likely to make key decisions and to act as physical and emotional barriers to information sharing between the oncologist and patient. In high-income countries, there is evidence to suggest that family meetings may enhance family-patient-team communication. ${ }^{42}$ Fourth, our data suggests that patients conceal their concerns. Within the model, this appears to be driven to the stigma surrounding diagnosis and poor prognosis that is enacted by collusion between clinicians and families, keeping the patient's focus on cure and recovery. Intervention must empower patients to share their concerns beyond physical pain, to the extent that they wish by reducing perceived or internalised stigma. This will require oncology and palliative care services to use terminology that identifies palliative care as being more than simply a physical pain service, and enabling families to hear patient distress. Fifth, interventions must be developed from an expanded theory of stigma in advanced cancer, refining our model from the exploratory data using data from a wider geographical sample of oncologists, patients and families in India.

Our novel theoretical model is an essential first step to ensure that any proposed complex intervention is plausible and has a proposed mechanism of action that addresses all relevant stakeholder populations. Taking a family-centred approach, with an oncology workforce skilled in communication and an enabled patient population may be feasible and acceptable. Through this, improved access to palliative care with improved outcomes may be attainable.

Acknowledgements We acknowledge the support of Dr Subhash Tarey, Dr Renuka Pai, Sr. Sudha Daniel and Sr Shaifali Dsouza in identifying potential participants and inviting them into this study. We would like to thank Akshatha Jagadeesha for coordinating the patient and family interviews, transcriptions and translations. Lastly, we thank the patients and family members for their time and willingness to share their thoughts with us on these sensitive issues.

Contributors The study was conceived by ME, SN and RH, SN was local PI and analysis was led by RH with ME and SN reviewing and agreeing the data coding frame. The interpretation of findings was jointly by RH, SN and ME, and all authors contributed to and approved the final manuscript. RH led the drafting of the manuscript with contribution by all authors and final approval by all authors.
Funding This study was supported by grant R01MH095659.

Competing interests None declared.

Patient consent for publication Not required.

Ethics approval All procedures were approved by the Institutional Review Boards at St John's Medical College Hospital (ref: 222/2016), the University of California, San Francisco (ref: 174866), and Kings College London (ref: HR- 16/17 - 3820).

Provenance and peer review Not commissioned; externally peer reviewed.

Data sharing statement The raw data (transcripts) are available from the corresponding author upon reasonable request by email.

Open access This is an open access article distributed in accordance with the Creative Commons Attribution Non Commercial (CC BY-NC 4.0) license, which permits others to distribute, remix, adapt, build upon this work non-commercially, and license their derivative works on different terms, provided the original work is properly cited, appropriate credit is given, any changes made indicated, and the use is non-commercial. See: http://creativecommons.org/licenses/by-nc/4.0/.

\section{REFERENCES}

1. International Agency for Research on Cancer. In: Bernard L, Peter $\mathrm{B}$, World cancer report. edn: International Agency for Research on Cancer, 2008.

2. Kanavos $P$. The rising burden of cancer in the developing world. Annals Oncol 2006;8:viii15-viii23.

3. Krüger C. Childhood cancer treatment in developing countries. The Lancet 2005;365:752-3.

4. Worldwide Palliative Care Alliance, Organization WH. In: Connor S, Sepulveda M, eds. Global Atlas of palliative care at the end of life: Worldwide Palliative Care Alliance, Organization WH, 2014.

5. Gwyther L, Brennan F, Harding R. Advancing palliative care as a human right. J Pain Symptom Manage 2009;38:767-74.

6. Beaglehole R, Bonita R, Horton R, et al. Priority actions for the noncommunicable disease crisis. Lancet 2011;377:1438-47.

7. WHA6. Strengthening of palliative care as a component of comprehensive care throughout the life course WHA6. 2014 http:// apps.who.int/gb/ebwha/pdf_files/WHA67/A67_R19-en.pdf

8. Organisation. WH. Universal health coverage. http://www.who.int/ mediacentre/factsheets/fs395/en/ (Accessed 08th Feb 2018).

9. WHO. Disease burden and mortality estimates. $2018 \mathrm{http}: / / \mathrm{www}$. who.int/healthinfo/global_burden_disease/estimates/en/ (Accessed 28th Sep 2018).

10. Lynch T, Connor S, Clark D. Mapping levels of palliative care development: a global update. J Pain Symptom Manage 2013;45:1094-106.

11. Kumar S. Models of delivering palliative and end-of-life care in India. Curr Opin Support Palliat Care 2013;7:216-22.

12. Harding R, Powell RA, Kiyange F, et al. Provision of pain- and symptom-relieving drugs for HIV/AIDS in sub-Saharan Africa. J Pain Symptom Manage 2010;40:405-15.

13. Group UoW-MPPS. Consumption data at-a-glance - India. http:// www.painpolicy.wisc.edu/country/profile/india

14. Singh T, Harding R. Palliative care in South Asia: a systematic review of the evidence for care models, interventions, and outcomes. BMC Res Notes 2015;8:172.

15. Mahal A, Karan A, Fan VY, et al. The economic burden of cancers on Indian households. PLoS One 2013;8:e71853.

16. Pramesh CS, Badwe RA, Borthakur BB, et al. Delivery of affordable and equitable cancer care in India. Lancet Oncol 2014;15:e223-33.

17. Rao A, Ekstrand M, Heylen E, et al. Breaking bad news: patient preferences and the role of family members when delivering a cancer diagnosis. Asian Pac J Cancer Prev 2016;17:1779-84.

18. Broom A, Doron A. The rise of cancer in urban India: Cultural understandings, structural inequalities and the emergence of the clinic. Health 2012;16:250-66.

19. Broom AF, Doron A. Traditional medicines, collective negotiation, and representations of risk in Indian cancer care. Qual Health Res 2013;23:54-65.

20. Laxmi S, Khan JA. Does the cancer patient want to know? Results from a study in an Indian tertiary cancer center. South Asian J Cancer 2013;2:57-61.

21. Shen MJ, Hamann HA, Thomas AJ, et al. Association between patient-provider communication and lung cancer stigma. Support Care Cancer 2016;24:2093-9.

22. Gupta A, Dhillon PK, Govil J, et al. Multiple stakeholder perspectives on cancer stigma in north India. Asian Pac J Cancer Prev 2015;16:6141-7. 
23. Harding R. Informal caregivers in home palliative care. Prog Palliat Care 2013;21:229-31.

24. Marin G, Marin B. Research with hispanic populations: SAGE, 1991:148.

25. Glaser B. The constant comparative method of qualitative analysis. Soc Probl 1965;1:436-45.

26. Justo Roll I, Simms V, Harding R. Multidimensional problems among advanced cancer patients in Cuba: awareness of diagnosis is associated with better patient status. J Pain Symptom Manage 2009;37:325-30.

27. Ganca LL, Gwyther L, Harding R, et al. What are the communication skills and needs of doctors when communicating a poor prognosis to patients and their families? A qualitative study from South Africa. $S$ Afr Med J 2016;106:940-4.

28. Stanford J, Sandberg DM, Gwyther L, et al. Conversations worth having: the perceived relevance of advance care planning among teachers, hospice staff, and pastors in Knysna, South Africa. J Palliat Med 2013;16:762-7.

29. Bharat S, Ramakrishna J, Heylen E, et al. Gender-based attitudes, HIV misconceptions and feelings towards marginalized groups are associated with stigmatization in Mumbai, India. J Biosoc Sci 2014;46:717-32.

30. Malavé S, Ramakrishna J, Heylen E, et al. Differences in testing, stigma, and perceived consequences of stigmatization among heterosexual men and women living with HIV in Bengaluru, India. AIDS Care 2014;26:396-403.

31. Ekstrand ML, Ramakrishna J, Bharat S, et al. Prevalence and drivers of HIV stigma among health providers in urban India: implications for interventions. J Int AIDS Soc 2013;16:18717.

32. Steward WT, Bharat S, Ramakrishna J, et al. Stigma is associated with delays in seeking care among HIV-infected people in India. J Int Assoc Provid AIDS Care 2013;12:103-9.
33. Ekstrand ML, Bharat S, Ramakrishna J, et al. Blame, symbolic stigma and HIV misconceptions are associated with support for coercive measures in urban India. AIDS Behav 2012;16:700-10.

34. Steward WT, Herek GM, Ramakrishna J, et al. HIV-related stigma: adapting a theoretical framework for use in India. Soc Sci Med 2008;67:1225-35.

35. Miyata H, Takahashi M, Saito T, et al. Disclosure preferences regarding cancer diagnosis and prognosis: to tell or not to tell? $\mathrm{J}$ Med Ethics 2005;31:447-51.

36. Miyata $\mathrm{H}$, Tachimori $\mathrm{H}$, Takahashi M, et al. Disclosure of cancer diagnosis and prognosis: a survey of the general public's attitudes toward doctors and family holding discretionary powers. BMC Med Ethics 2004;5:E7.

37. Yun YH, Kwon YC, Lee MK, et al. Experiences and attitudes of patients with terminal cancer and their family caregivers toward the disclosure of terminal illness. J Clin Oncol 2010;28:1950-7.

38. Yun YH, Lee CG, Kim SY, et al. The attitudes of cancer patients and their families toward the disclosure of terminal illness. J Clin Oncol 2004;22:307-14.

39. Shah SM, Heylen E, Srinivasan K, et al. Reducing HIV stigma among nursing students: a brief intervention. West $J$ Nurs Res 2014;36:1323-37.

40. Radhakrishna K, Dass D, Raj T, et al. Development of a novel tabletbased approach to reduce hiv stigma among healthcare staff in India. Perspect Health Inf Manag 2017;14:1b.

41. ICRW. Blueprint for reducing HIV stigma in India: international center for research on women. (Accessed 25 Mar 2018).

42. Cahill PJ, Lobb EA, Sanderson C, et al. What is the evidence for conducting palliative care family meetings? A systematic review. Palliat Med 2017;31:197-211. 